\section{PHYSIOLOGICAL LABORATORIES IN GREAT BRITAIN}

THE introductory paragraph with which you bring under the notice of your readers the very excellent description of the Physiological Laboratoly at Leipsic by Dr. H. P. Bowditch, of Boston, begins with the phrase: "In England we have absolutely no Physiological Laboratory open for students." As this statement appears to me to admit of misconstruction, as leading to the inference that the present neglect of physiology in England is entirely due to the want of opportunities, it seems desirabie to place before those of your readers who are interested in the subject, the actual position of this country as regards facilities for this kind of research.

There is, at all events, one institution in London, viz. University College, in which, for many years past, it has been possible for any man desirous of conducting experimental inquiries in Physiology or Pathology to do so; in proof of which I may refer to the experiments of the scientific committees of the Medical and Chirurgical Society on Apnæa and on subcutaneous injections; to my own experiments on the transmission of cholera to the lower animals, and on the influence of the respiratory movements on the action of the heart-all of which inquiries were made in the Physiological Laboratory of University College by persons unconnected with the Institution. In this enumeration I make no reference to the more abundant similar work which has been done by professors and siudents of the College, because my only object is to show that, as regards London at all events, it is many years since it could be said with truth that there was no Physiological Laboratory open to students.

At the present moment there are laboratories connected with one or two of the principal medical schools in this country to which students are admissible. In Edinburgh the Physiological Laboratory is fitted with all the instruments and appliances for research which are to be found in the laboratories of Germany; and for some time the students have been superintended in their studies by practical teachers, thoroughly versed in those methods of exact research which have been lately introduced into vital physics. In addition to the Physiological Laboratory, which is under the direction of Professor Bennett, the Professor of Medical Jurisprudence (Dr. Maclagan), and the Professor of Materia Medica (Dr. Christison) severally open their laboratories without charge, only requiring those who profit by them to meet the current expenses of research. Further, Dr. Arthur Gamgee, Lecturer on Physiology at the Royal College of Surgeons, has opened a new laboratory in which several separate inquiries are now being carried on. In Edinburgh, therefore, little can be said of want of opportunities; and here again the best proof of the existence of the means is to be found in the results attained, i.e. in the laboratory work actually performed by Edinburgh students during the last few years, as, for example, the researches of Dr. Fraser on Calabar Bean, of Dr. McDougall on the action of phosphorus, of Dr. Paton on the active principles of Broom, of Dr. Brunton on Digitalis, of Dr. Keith Anderson on the excretion of urea in typhus, of Dr. Young on the quantity of iron in bile, of Dr. Rutherford (now of King's College) on the vagus nerve, and others which might be mentioned, all of which possess the essential characteristics which constitute scientific value, though differing very considerably from each other in completeness. That so much has been already accomplished affords encouragement for the hope that as soon as the obstacles which still exist in the way of the student have been removed, Edinburgh will stand behind very few of the German schools of medicine in scientific productiveness. Of these obstacles, the most serious is that of expense. The large fees which are demanded, particularly for the physiological laboratory, have restricted the number of workers, the best of whom, as your correspondent, Prof. Stricker, so well pointed out in one of his recent communications, are not to be found either in England or Germany among the well-to-do.

It must be admitted that at the present moment our great London Schools are behind those of Edinburgh, as regards means of physiological and pathological research. There are, however, good reasons for anticipating that in a very few years the aspect of things will be entirely changed. In King's College a physiological laboratory already exists, to which I understand students are admitted. I am not aware to what extent it contains the necessary accommodation, but it is certain that those who work in it have at all events the supervision and aid of a teacher thoroughly conversant with the art of investigation, At Guy's, Bartholomew's, and St. Thomas's I hear that similar improvements are at all events in contemplation. At University College, which, as has already been said, has long afforded opportunities not to be had elsewhere, these have been much extended during the present year. The Physiological Laboratory now consists of three rooms, one of which, of large size, is devoted to students, one is employed as a place of research and for the preparation of materials for demonstration, while the third is used for such special purposes as require a separate apariment.

The movement towards a more practical method of teaching the theory of medicine, of which the facts I have referred to afford evidence, is a new one. In the course of very few years it may be confidently anticipated that great progress will be made, and that although we cannot in so short a time hope to compete with the splendid institutions which exist at Leipzig or at Breslau, where spacious buildings, costly instruments, and abundant material, are freely placed at the disposal of the siudent without charge and without respect to his nationality, or any other consideration except his competency, we may hope to produce results which may be of equal importance for the advancement of Science.

At the present moment, the want which perhaos presses even more than that of laboratories, is that of workers in physiology - that is, of men already orilled in chemistry and physics, and prepared to devote a few years of their lives to continuous physiological or pathological research. The reason why such men are warting is no doubt in great measure that hitherto the opportunities for work have been denied them. Another, and perhaps more efficient reason, is that the statement which is so often repeated in lectures, that medicine is based on physiology, is not really believed or accepted. Consequently, young physicians, instead of devoting their time and energies to research-whether conducted in the hospital wards or in the laboratory-spend the best years of their lives in the collection and exhibition of curiosities from the dead-house (miscalled pathology), in the compiling of masses of useless statistics, or in the performance of other drudgeries, as little conducive to their own improvement as to the advancement of medicine.

If it were not for the want of this scientific conviction, or, if I may venture to use the expression, scientific faith, the study of vital physics would make rapid progress in England, notwilhstanding all the material obstacles which stand in their way. A dozen years of good work would place us again side by side with Germany, instead of being, as now seems possible, in danger of being overtaken by America.

This country still maintains its superiority over all other European countries in respect of medical and surgical skill, and has reason to be proud of it. But it is to be borne in mind that the men who exercise that skill were for the most part educated at a time when we cou'd also compete with Germany in Science. As Science advances, its intluence on practice, now so difficult to trace, will increase. If we continue to undervalue it as we have done, shall we not also eventually lose our practical preeminence?
J. BURDON SANDERSON 